\title{
Study on the degree of use and knowledge of digital marketing elements in Romanian small and medium enterprises
}

\author{
Răzvan Mihai Dobrescu ${ }^{1, *}$, Cristina Petronela Simion ${ }^{1}$, Iuliana Grecu ${ }^{1}$, and Cristian Aurelian Popescu ${ }^{1}$ \\ ${ }^{1}$ Politehnica University of Bucharest (UPB); Faculty of Entrepreneurship, Business Engineering and Management
}

\begin{abstract}
This paper aims to identify digital marketing elements, to analyze and to study the industry's degree of knowledge regarding digital marketing, as well as the degree of use of digital technology in the marketing mix of small and medium enterprises(SME's) in Romania. First of all, the basic concepts of digital marketing will be defined and analyzed: e-bussines, e-commerce and e-marketing, and then, in order to identify the degree of knowledge of these elements as well as the degree of use in the promotion process, a statistical research was carried out which had the following objectives: to determine the degree to which SMEs in Romania know the concepts of digital marketing; to identify whether these organizations have developed digital marketing strategies; to identify whether there are people or groups of people who are responsible for digital marketing activities at the organization level.
\end{abstract}

\section{Introduction}

We are witnessing today, in a world based on real-time communications, the emergence of new challenges that benefit some and disadvantage others. Thus, the information society, one of the most important factors of the business environment, has made it possible, through digital marketing, for real mutations to appear in everyday life that we would not even have thought about a few years ago.

In a dynamic world marked by rapid technological and economic change, SME's have to adapt and seek new ways to improve their business [1]. While customer requests are on the rise, companies are forced to do more with the same or even fewer resources.

Micro, small and medium-sized enterprises (SME) play an important role in today's society and economy, since they represent $99 \%$ of all enterprises in the European Union (EU) [2].

They have always been a central pillar of economic and social life of any country, underpinning the development of the economy and making a major contribution to growth and job creation. The innovative potential, dynamism, flexibility, adaptability and mobility are some of the characteristics that SMEs have and which are considered essential for the development of the economy of any country. Starting from these things, and wishing to build a strong economy, the European Union aims to strengthen the entrepreneurial spirit and create conditions for the development of innovative practices that ultimately increase the performance of SMEs [3].

Marketing and marketing specialists, today need to be open minded and to interlink their efforts with those of their IT colleagues to create profitable synergys that help improve the implementation of marketing strategies and to reward efforts in this regard by obtaining the necesary feedback in real time in order to establish future directions [4].

The elements behind this study stem from the companie's confusion about the differences between concepts of : digital marketing, e-marketing, e-business and e-commerce. Often, those terms overlap, but marketing specialists share the oppinion that the term digital marketing is more comprehensive and its scope of application includes e-business elements (IT infrastructure through which the organization's business strategy is implemented), e-commerce (purchasing and selling) and e-marketing (efforts to promote and sell services on the Internet).

Based on the literature there are clear research gaps in the field of E-Marketing especially in the areas of EMarketing performance as well as E-Marketing adoption in Small Business enterprises (SBEs). To fill such gaps, there is a need for conducting more research to investigate the relationship between implementing EMarketing and SMEs performance [5].

In the paper of [6] results suggest that e-business use emerges from technological and internal organizational resources rather than from external pressure. In addition, results show that e-business use contributes positively to firm performance through organizational innovation.

SME has bright future when they can take an advantage of information technology [7]. Beside cost reducing, they can reach wider market share. E-commerce is one of the solution to promote SME products. It was not enough to implement ecommerce without consider the success factor [8].

Starting from this information, the present paper aims to identify the current level of penetration and the degree of knowledge of the digital marketing elements as well as

\footnotetext{
* Corresponding author: author@e-mail.org
} 
the degree of use of digital technology in the promotion process carried out in SMEs in Romania, as we consider that these elements can lead to increasing organizational performance .

\section{Methodology}

The main research method used was the survey, and the main research tool, the questionnaire. Several types of closed questions, as well as appreciation scales, were used to design the questionnaire.

The most costly and most prone to error is the information gathering stage. In the case of investigations, there are four types of problems that we certainly took into consideration, namely: they do not answer honestly, they are hard to get by, they are dishonest and they do not respond at all.

To obtain the raw data, research based on the questionnaire was used. The tool used was the online questionnaire, considering it to be more appropriate to the subject of the paper, it is easy to manage and complete, cost management is reduced compared to other survey tools, the advantage of overcoming spatial and temporal areas [9]. In addition to these advantages, the on-line questionnaire also has some limitations: it is a selfadministered questionnaire because additional explanations may be needed on how to fill in the questions, managing the online questionnaire can not be controlled and supervised by an interviewer and due to the lack of the interviewer, abandonment of the questionnaire completion can be recorded.

The questionnaire was designed and designed to meet the proposed objectives. For the final form of the questionnaire, a small group of specialists, both in digital marketing and in statistical surveys, was consulted resulting in several improvement loops, until the final form was sent to the respondents. This final form of the questionnaire contains a total of 32 questions, but in this paper only the answers from some of them are used, as the rest will be the subject of another research.

In order to draw the appropriate conclusions, in the information analysis step, the collected data will be analysed using the IBM-SPSS program, dedicated to statistical study.

\section{Results}

As stated before, the questionnaire was sent directly by the team members to small and medium size romanian companies and the rate of response was above expectations. Small companies with less than 9 employees and a turnover of less than 2 million Euro account for $48.6 \%$ of all the completed questionnaires. The other half of the responses is divided among small enterprises with no more than 49 employees that account for $22.9 \%$ of answers, medium enterptises with no more than 249 employees that account for $25.7 \%$ of all respondents and non-proffit organizations that represent only $2.9 \%$ off our sample.

When analysing the business sectors of the respondent companies we can see that the best represented sector is
IT\&C accounting for $20 \%$ of the companies while construction and commerce account for $11.4 \%$ of respondents each. All other sectors represent less than $10 \%$ of the sample and are not especially mentioned. The fact that more than $30 \%$ of the respondent companies come from IT\&C and commerce that are two fields that should heavily rely on digital marketing as the main channel for promoting their products should be considered when analysing the overall results.

A very important metric for our study consists of the age of the company, as we expect that younger companies will use digital marketing to a more extended degree than the well established older competitors. This is due to the fact that younger companies ten to be entrepreneurial, dynamic and have smaller marketing budgets. On the other hand, older companies tend to have larger marketing budgets and this allows them to have a strong online presence and also a larger number of years of presence in the market should allow them the time to consolidate their online footprint. In our sample $34.3 \%$ of the respondent companies were formed between 2000 and 2009 and have been on the market for more than 10 years. Only $20 \%$ of them were formed in the recent years, starting with 2010 and the other categories are made up by companies that were set up between 1990 and 1999 and account for $21.9 \%$ of the sample while companies with more than 30 years in the market account for $23.9 \%$ of respondents.

Then we asked the respondents to asses their online presence on a scale from 1 to 5 . As expected we found a relatively strong online presence with more than $50 \%$ of the companies evaluating their online presence with 4 and 5. $19.4 \%$ of all companies said that they have a medium presence online while the other $30.5 \%$ a low one.

Investigating further we found that out of the $50 \%$ of companies that assessed their online presence as high, the larger part were older companies, established before 1990. This category accounted for $38.9 \%$ of the respondents while only $5.6 \%$ of them were companies established after 2010 as shown in Fig.1.

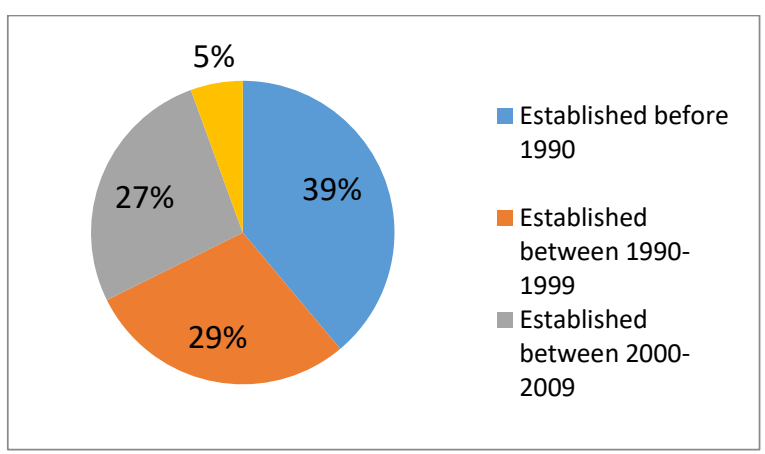

Fig.1. Companies with strong online presence

Even if it was expected than younger companies would be more inclined to using modern digital marketing tools, it is clear that in the case of well established companies the extra time and the availability of founding had a larger influence on the use of digital marketing.

On the other side, among companies that reported a low online presence, $44.4 \%$ were companies established after 2010 and $33.1 \%$ were companies established 
between 2000 and 2009. Of the companies that reported a low online presence only $10 \%$ were established prior to 1990.

In Fig.2. we can see that companies established before 200 have reported a better online presence than the younger competitors that reported only a medium and weak position.

When asking about the existence of a digital marketing strategy in the company, $40 \%$ of the respondents answered that they don't have a digital marketing strategy implemented and among them 53\% said that such a strategy will be developed and implemented. Out of the companies that reported not having a digital marketing strategy, $57.3 \%$ are young companies established after the year 2000 .

Most of the copanies in the sample, $71.4 \%$, reported to have one or more employees that are responsable for digital marketing activities. The rest of $21.4 \%$ use outsourcing in order to coordinate the digital marketing activity and $7.1 \%$ do not have anyone responsable for this type of activity. Out of all the companies $35.7 \%$ reported to employ a person responsable for all types of activities (e-business, e-commerce and e-marketing), 28.6\% only have a person responsable for e-marketing activities and $7.1 \%$ of them have a person responsable for e-commerce activities.

When asked how familiar the marketing manager is with the terms of ebusiness, e-commerce and e-marketing we found that most of them knew what e-commerce and e-marketing mean. In the case of e-marketing, $57.3 \%$ of the respondents said they are familiar or very familiar with the term while only $17.2 \%$ admitting to having limited knowledge of the meaning of the term. In the case of e-commerce $53.6 \%$ of managers reported a good and very good understanding of the term meaning and $21.3 \%$ reported being less familiar with the term. Regarding ebusiness, the level of knowledge reported by managers is lower than for the other two terms. Only $46.4 \%$ of them reported to be familiar or very familiar with the meaning of e-business, while $3.6 \%$ of them admitted to have never heard of the term.

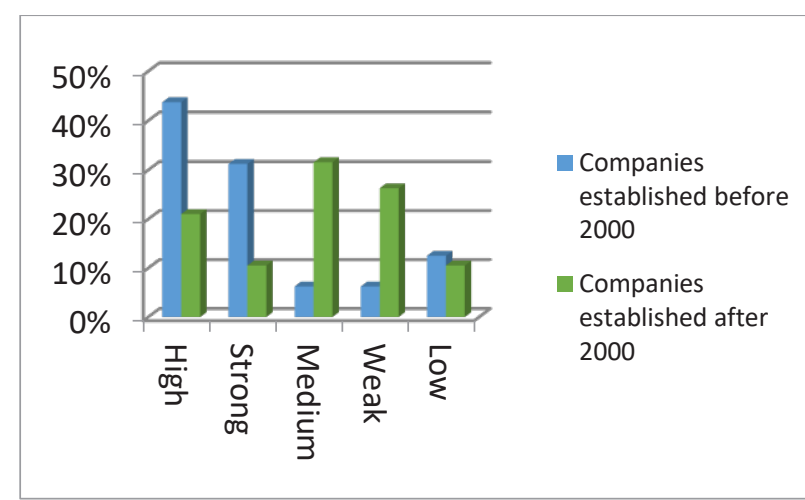

Fig.2. Distribution of companies by online presence

Out of the managers that reported a strong knowledge of the three terms of e-business, e-commerce and emarketing, $21 \%$ reported a medium online presence and not having a digital marketing strategy in place but willing to implement one in the next year. In all those cases the answers came from young companies established after 2010 and we can assume that the lack of time or a tight marketing budget are the factors affecting their moderate usage of modern digital marketing techniques.

When asked if there is any difference between the meaning of the terms ebusiness, e-commerce and emarketing, $75 \%$ of the managers reported they consider that there are differences between the three terms and $25 \%$ of them admitted to not know if there are differences. All of the $25 \%$ of the managers that did not know wether there are differences among the three termms, also reported to be less familiar or have medium knowledege about each of the terms.

In order to asses the degree of penetration of new digital marketing techniques within the companies we asked the managers witch of the digital marketing components ( PPC campaigns; Social Media campaigns; Display Advertising; SEO; Content Marketing; E-Mail Marketing; Website; Mobile...) ranks the first when ordered by budget. Not surprisingly, almost $43 \%$ of the respondents said that website maintenance and improvement have the largest budget out of all digital marketing components. Other three components came at closed results. PPC campaigns have the largest budget in the case of $14,3 \%$ of the respondents and for $13,9 \%$ and $13,4 \%$ of them, Social Media campaigns and Display Advertising campaigns rank the first in terms of money spent by the company for digital marketing.

\section{Conclusions}

Our study's main goal was to to identify the main digital marketing elements and to study and analyze the industry's degree of knowledge regarding digital marketing, as well as the degree of use of digital technology in the marketing mix of SMEs in Romania. For this purpose we used a questionnaire that was sent to a large number of companies and the results were analysed by the team in order to draw conclusions on the main factors that influence the use and adoption of digital marketing techniques.

We aimed at profiling the companies that regularly use digital marketing elements in promoting their products and at understanding what are the key characteristics of those firms.

We found out that digital marketing is a fairly new concept for the Romanian managers and that only around $53 \%$ of them are familiarized with terms from digital marketing. Surprisingly, $21 \%$ of the managers that reported a strong knowledge of the three terms of ebusiness, e-commerce and e-marketing and understood the importance of on-line presence, also reported a medium online presence and not having a digital marketing strategy in place in their companies. When asked if there is any difference between the meaning of the terms ebusiness, e-commerce and e-marketing, 25\% of the respondents admitted to not know if there are differences.

We found out that more than $50 \%$ of the companies consider to have a relatively strong online presence and out of them the larger part were older companies, 
established before 1990. The older companies made up for around $39 \%$ of the high online presence respondents. Those findings tell us that even if it was expected that younger companies would be the category that used modern digital marketing tools the most, it is clear that in the case of well established companies the extra time and the availability of founding had a larger influence on the use of digital marketing techniques.

In order to strengthen our conclusion on the limited penetration of digital marketing techniques in Romanian SMEs, the main focus in terms of allocation of funds in those companies is the maintenance and improvement of website and not the newest and more sophisticated categories of mobile marketing or content marketing.

Acknowledgement: This work has been funded by University Politehnica of Bucharest, through the "Excellence Research Grants" Program, UPB - GEX 2017. Identifier: UPBGEX2017, Ctr. No. 94/25.09.2017 (IMkDiP_IMM).

\section{References}

1. M. Robu,, Use of social media components in bussines-SME's point of view(Utilizarea componentelor Social Media în mediul de afaceri perspectiva IMMurilo)r, Munich Personal RePEc Archive, MPRA Paper No. 44585, posted 7, (2013)

2. P. Kuller, M. Vogt, D. Hertweck, M. Grabowski, $A$ Domain Specific Approach Journal of Innovation Management in Small \& Medium Enterprises. IT Service Management for Small and Medium Sized Enterprises, (2012)

3. L.D. Anghel, E. Matei, Marketing for SME (Marketingul intreprinderilor mici și mijlocii), Editura ASE, (2005)
4. C.D. Gostian, Research on marketing of professional training services in the online environment (Cercetare privind marketingul serviciilor de formare profesională $\hat{\imath}$ mediul online), Cluj Napoca, (2015)

5. Hatem El-Gohary, E-Marketing - A literature Review from a Small Businesses perspective, International Journal of Business and Social Science, Editor, Centre for Promoting Ideas, USA, Volume 1, Issue 1, (2010)

6. P. Soto-Acosta, S. Popa \& D. Palacios-Marqués, Ebusiness, organizational innovation and firm performance in manufacturing SMEs: an empirical study in Spain, Technological and Economic Development of Economy, Volume 22, 2016 - Issue 6,(2016),https://doi.org/10.3846/20294913.2015.107 4126

7. R. Pulfer, O. Bucovetchi, Understanding the Organization's Readiness for Change, Central and Eastern European Lumen Conference on New Approaches in Social and Humanistic Sciences, Chisinau, Moldova, politica de finanţare.453-458, ed. Medimond, (2016), WOS: 00039152150008

8. F. Fahruzzaman, A. Pribadi Subriadi, An Analysis of E-Commerce Adoption for Small and Medium Enterprises in Indonesia, IPTEK Journal of Proceedings Series, Volume 2, No. 1, (2015), DOI: http://dx.doi.org/10.12962/j23546026.y2015i1.1046

9. G. Grossek, Email for marketing research, Revista de Informatică Economică, (2004 